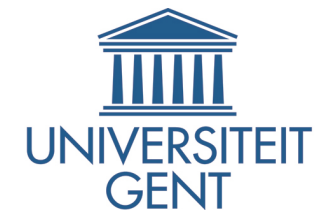

biblio.ugent.be

The UGent Institutional Repository is the electronic archiving and dissemination platform for all UGent research publications. Ghent University has implemented a mandate stipulating that all academic publications of UGent researchers should be deposited and archived in this repository. Except for items where current copyright restrictions apply, these papers are available in Open Access.

This item is the archived peer-reviewed author-version of:

The relationship between spatial proximity and travel-to-work distance: The effect of the compact city

Boussauw, K., Neutens, T. \& Witlox, F.

In: Regional Studies (forthcoming)

To refer to or to cite this work, please use the citation to the published version:

Boussauw, K., Neutens, T. \& Witlox, F. (2011). The relationship between spatial proximity and travel-to-work distance: The effect of the compact city. Regional Studies (forthcoming). 
Important: This is a draft version that should not be cited. The final paper will be published in a forthcoming issue of Regional Studies. Publication status can be checked at http://www.informaworld.com/smpp/title $\sim \mathrm{db}=$ all $\sim \operatorname{content}=\mathbf{t 7 1 3 3 9 3 9 5 3}$

\title{
The Relationship Between Spatial Proximity and Travel-to-Work Distance: The Effect of the Compact City
}

Kobe BoussauW*, TiJs NeUtens and FRANK WitLOX

Geography Department, Ghent University, Krijgslaan 281/S8, 9000 Gent, Belgium. Emails: kobe.boussauw@ugent.be,tijs.neutens@ugent.be,frank.witlox@ugent.be

* corresponding author

\begin{abstract}
In this paper, an assessment is made of the relationship between selected aspects of spatial proximity (density, diversity, minimum commuting distance, jobs-housing balance and job accessibility) and reported commuting distances in Flanders (Belgium). Results show that correlations may depend on the considered trip end. For example, a high residential density, a high degree of spatial diversity and a high level of job accessibility are all associated with a short commute by residents, while a high job density is associated with a long commute by employees. A jobs-housing balance close to one is associated with a short commute, both by residents and by employees. In general, it appears that the alleged sustainability benefits of the compact city model are still valid in a context of continuously expanding commuting trip lengths.
\end{abstract}

Keywords

compact city, spatial proximity, commuting, sustainable spatial development, Flanders 


\title{
JEL index numbers
}

\author{
$\mathrm{R} 14, \mathrm{R} 23, \mathrm{R} 40$
}

\section{Introduction}

Although the spatial development model of the 'compact city' gained momentum in the planning literature particularly during the 1980 s, there are still many prevailing spatial policy plans that draw from this concept. One of those is the Spatial Structure Plan for Flanders, that was adopted in 1997 (MINISTRY OF THE FLEMISH COMMUNITY, 1997/2004) and was inspired, among others, by the EU's "Green paper on the urban environment" (COMMISSION OF THE EUROPEAN COMMUNITIES, 1990) and The Netherlands' "Fourth report on spatial planning" (MINISTRY OF Housing, SPATIAL PlanNing AND THE ENVIRONMENT, 1988).

In Europe, the concept of the compact city emerged from a visionary quest for a model of sustainable urban development, based on a city tailor-made for pedestrians and cyclists, with a relatively high density, a high degree of functional mix and efficient public transport (JENKS et al., 1996, p. 5). In North America, the New Urbanism concept can be considered the counterpart of the compact city model, offering an express alternative for the typically American, extensive form of suburbanisation (ELLIS, 2002), although there are differences in terms of scale (New Urbanism occurs usually in small scale developments that are strongly oriented towards walking). Apart from the protection of open space and economics of scale, the motivation for compact city development is to a large extent grounded on the sustainability of mobility patterns. Encouraging trips over short distances and creating spatial conditions that stimulate walking, cycling and using public transport are key ingredients of the compact city model. The model has been criticized because of the potential of larger social problems in residential neighbourhoods with high densities, the concentration of pollution in living environments and the increasing risk of congestion (BURTON, 2000). However, the benefits of enhanced spatial proximity and reduced car dependence are rarely questioned. 
In reality the distinctly demarcated, quasi-walled, compact city gradually disappeared since the 19th century. The density gradient from the Alonso-Muth-Mills model (describing the equilibrium between the distance to the CBD and real estate demand in a mono-centric urban system) corresponds much better to reality, even though in the post-war western world it was overtaken by the development of urban sprawl, in which historical centres are usually embedded. However, this does not mean that mobility influencing characteristics that are attributed to the compact city are completely absent in suburbanized and even sprawled areas.

Sustainable urban development implies offering more opportunities for travel over short distances, and encouraging the use of alternative transport modes (instead of the private car). These two objectives are not independent. If the demand for long-distance travel is reduced, slower transport modes, that are usually less environmentally stressful, are likely to be chosen more often. BOUSSAUW and WITLOX (2009) show that at a regional scale the distance travelled per person can be considered a good approximation for the overall sustainability of the commute, since positive consequences of modal shifts (especially towards train) are often counterbalanced by increases in average trip length, while a reduction of trip lengths may result in a modal shift towards low-impact modes such as cycling and walking. These patterns result in a correlation between energy consumption (as a sustainability indicator) and distance travelled that is even stronger than intuitively expected. Furthermore, many recent policy plans (as in our study area: the Mobility Plan for Flanders and the Flemish Climate Policy Plan) overemphasize encouraging a modal shift, while research into the number of kilometres travelled has faded somewhat into the background. This justifies an approach in which the distance travelled is considered a sole sustainability indicator, although we are well aware that reality is significantly simplified by not taking into account modal split, congestion and other factors that influence the environmental impact of travel.

Within the scope of this paper we examine whether and to what extent there is a discernible link between the alleged qualities of the compact city and the travel patterns of its users on the basis of commuting data for Flanders and Brussels. To this end, we not only focus on cities, but on the presence of characteristics attributed to the compact city model throughout the suburbanised historically polycentric spatial structure that characterizes this region. More specifically, the present 
paper attempts to gain a deeper understanding of the observed spatial variation in trip lengths on the basis of commuting data available for Flanders and Brussels. The restriction to home-to-work travel is motivated by the need for accurate data: in Belgium commuting is the only category of travel that is surveyed area-wide. Also, the study of the commute is particularly relevant from an environmental point of view, given that the longest average trip lengths are recorded in this travel category (see e.g. ZWERTS and NUYTS 2004).

Although today a large body of literature describes aspects of the relationship between spatial structure and trip lengths, this paper adds considerably to the issue. One of the major difficulties regarding the realistic interpretation of previous studies is the uncertainty about the spatial scale at which the influence of certain spatial characteristics manifest. Much research has been done on monocentric urban structures, in a way neglecting the spatial characteristics that reflect the embeddedness in the larger region (e.g. CERVERo, 1996; PENG, 1997; WANG, 2000; SCHWANEN and MoKhtARIAN, 2005a). By studying a region that is characterized by a large spatial diversity, and by comparing a series of various spatial variables - which account for the characteristics of the surrounding area in different ways - we add to the general research framework on proximity and trip length and thus partly address the mentioned difficulty. In this way the validity of various computational methods for spatial proximity is examined explicitly. Moreover, the analysis is consistently applied to both origins of trips (in this case: residential locations) and destinations (in this case: work locations) in order to obtain more insight into the role played by the deviation in spatial distribution between both location patterns throughout the region. Although the approach adds to the complexity of the issue, it contributes to the practice of spatial planning by complementing the classical triad "density, diversity and design" that was introduced by CERVERO en KOCKELMAN (1997).

A second important contribution is to be found in the specific attention that is paid to methodological problems such as MAUP, spatial autocorrelation, non-linearity and multicollinearity. Although this paper does not aim to solve these issues directly, it does provide additional insight into the influence of the analytical methods used on obtained correlations and significances. For example, it is not inconceivable that in previous studies the apparent non-significance of assumed relationships between spatial phenomena was related to a non deliberate choice of the geographical scale. 
While our approach disregards personal variations in travel behaviour that are not inherently spatial which is indeed a major simplification - a purely geographical approach to the concept of proximity remains of major importance. Our argument for this is grounded in peak oil theory, which dictates that limited oil production will in the long run lead to an important increase in the mileage-related costs of mobility and give rise to the importance of spatial proximity (DODSON and SIPE, 2008).

The paper is structured as follows. In section 2, a summary of the literature on compact city characteristics and commuting trip length is presented. In section 3, a research methodology is developed, taking into account statistical issues and data limitations. In section 4, the results are analysed and confronted with our knowledge of the spatial structure of the study area, while section 5 discusses theoretical issues of scale level and origin versus destination. Finally, section 6 provides concluding remarks and outlines possible improvements by further research.

\section{Relevant literature}

\subsection{Characteristics of the compact city}

According to NEUMAN (2005), the most important mobility-influencing characteristics of the compact city consist of a high density, a high degree of functional mix and a fine-grained land use pattern. The rationale behind the pursuit of high densities stems from the work of NEWMAN and KENWORTHY (1989; 1999), who pointed out that global cities with more inhabitants per square kilometre consume less fuel per capita for transportation needs. A higher density ensures a critical mass of public transport patronage, but also enhances the potential for spatial interaction between humans based on short distances. While NEWMAN and KENWORTHY'S work has been criticized on many occasions (see for example, MiNDALI et al., 2004), their thesis is still widely supported in spatial planning practice.

A sound spatial mix of functions is another important, yet often equivocal feature of the compact city. In particular, it is unclear at which geographical scale this mixture can play its full role. In the most extreme case, a high degree of spatial mix boils down to self-sufficiency of jobs, shops, schools and other services per neighbourhood. While several authors have studied the influence of spatial characteristics on travel behaviour of residents at this district level (among them: FRANK and PIVO, 
1994; Cervero and Kockelman, 1997; Crane and Crepeau, 1998; SCHWANEN and MoKhtarian, 2005a, b), it may also be apposite to observe this kind of spatial mix at the level of a city or a region, at least with regard to the more specialized functions. That is because a small grain size may neglect economic agglomeration benefits at larger scales. Moreover, some activities (e.g. heavy industry) obviously need a lot of space, especially if desired or legally enforced environmental buffering is to be taken into account.

Although by the end of the nineties the debate on the compact city was transformed into a discourse on sustainable urban development (WILLIAMS et al., 2000), density and diversity were retained as important elements. CERVERO and KOCKELMAN (1997) argue that density, diversity and design are important spatial factors underlying travel behaviour, and focus on the scale of the neighbourhood, attributing an important role to the design of public space. STEAD et al. (2000) found that the size of the city and the proximity to key infrastructure are additional factors that determine the relationship between spatial structure and travel, while VAN ACKER et al. (2007) focus on the explanatory power of a range of social characteristics.

Based on these findings, we argue that high density, a sound land use mix and a small grain size are all spatial elements, amenable to modification by policy, that are part of an overarching spatial quality that we would like to call "spatial proximity".

A less frequently discussed, but nevertheless important aspect is the spatial scale at which the influence of certain spatial characteristics is at its maximum. In the literature on the compact city often no distinction is made between small towns and metropolises. In Flanders, the distance covered by an average trip (all purposes combined) amounts to 12.5 kilometres (one way). The average commuter even covers a distance of about 19 kilometres per ride between home and work (ZWERTS and NUYTS, 2004). For the UK, LYONS and CHATTERJEE (2008) found an average commuter trip length of 13.7 kilometres in 2002-2003. According to BANISTER et al. (1997), commuter trip lengths increase year after year in European and North American metropolitan areas. It is patent that the average trip length does no longer correspond with the scale of a compact city, at least in a Belgian context.

The scale problem is acknowledged by many authors. VAN WEE (2002), for example, suggests that the findings of NEWMAN and KENWORTHY $(1989 ; 1999)$, which are based on demarcated cities, cannot be 
applied to the Dutch Randstad conurbation, as this urban system is operating at a higher, regional scale level. ALBERTI (1999), on the other hand, refers to several possible approaches to a sustainable spatial structure, stating that at the regional level the settlement pattern is of interest while at the local level neighbourhood design is paramount. In short, the scale problem is well recognized, but not explicitly addressed yet. As will be shown in this paper, this is partly due to the fact that the quantitative analysis of scale effects is hampered by substantial methodological issues.

Based on these arguments, we hypothesize that the main compact city variables (density and land use mix) are insufficient to represent the differences in the spatial distribution of residential locations and job locations at the scale of the region, or the embeddedness in the surrounding area. Therefore in section 3.2 we introduce three additional variables that should grasp the issue in a more comprehensive way.

\subsection{Commuting trip length}

Although it may be intuitively understood that spatial proximity is a predominant determinant for commuting trip lengths, many studies indicate that personal, economic and behavioural factors play an important role too, making aggregate non-spatial variables even prevalent in explaining commuting trip lengths. Both CERVERO (1996), PENG (1997) and VAN ACKER and WitLOX (2010) find a positive, albeit relatively limited effect of income level on commuting distance. WANG (2003) is more specific: above a certain income threshold, employees tend to live again closer to their work, making the discerned relationship non-linear. Other socio-economic characteristics that were investigated in the literature are gender, race, number of workers per household, education and property status of the residence (WANG, 2000). In the same analyses, urban characteristics (in contrast with rural characteristics) are considerably associated with short commuting distances. Irrespective of the type of model, the construction of the spatial proximity variables and the available data used, generally low coefficients of determination are obtained, indicating that a number of unknown or non-quantifiable "spurious" variables are responsible for the largest share of the explained variance. 
However, this is not to say that the spatial aspect is unimportant. Rather, spatial structure is a rigid constraint that is not able to undergo rapid change. If transport would become more expensive, a scenario that may become reality one day under the influence of peak oil, then the role of spatial proximity will undoubtedly gain importance (DODSON and SIPE, 2008). Our research focuses on the relationship between spatial proximity and commuting distance, by testing the applicability of several possible indicators on a regional scale.

\section{Methodology}

\subsection{Research design}

The aim is to examine relationships between commuting trip lengths and a number of spatial characteristics of the zones where the surveyed trips have their origin and their destination. Since the analysis focuses on regional variations, we first explore possible relationships visually by confronting maps with our knowledge of the study area. Then, a quantitative analysis is conducted by calculating correlations between the average trip length and each of the other selected variables. The variables are aggregated within geographic zones, introducing effects of spatial autocorrelation and MAUP. To address this problem, the choice of an aggregation level that is adapted to the analysis is paramount.

The two most obvious variables that we include in this research are directly obtained from the compact city literature. These are density and spatial diversity. However, we want to add three additional spatial parameters: the theoretical minimum commuting distance (as a more sophisticated measure of proximity), the jobs-housing balance (as a measure of self-sufficiency of a zone regarding job supply) and the number of accessible jobs (as a measure of accessibility). In the next section we will explain how these three additional variables have been calculated. In our analysis, the dependent variable is trip length both for trips that depart from and arrive in each considered zone.

Relationships are deduced in two steps. First, we visualize all variables at an intermediate aggregation level to get an overview. This map allows for an initial impression of possibly present links. Subsequently, we apply an exploratory spatial correlation analysis at several aggregation levels, with the intention to quantify a number of relationships and to test their significance. Based on the initial 
results, we then select the most appropriate aggregation level for our analysis. Finally, we assess expected multicollinearity in variables and assumed linearity of relationships, aiming to detect redundancies and thus improve the interpretation of the results.

\subsection{Used data and variable construction}

In what follows, we discuss the origin and composition of the six used variables: distance per trip, density, diversity, minimum distance per trip, jobs-housing balance and number of potentially accessible jobs.

\subsection{1. $\quad$ Distance per trip (dpt)}

To determine the distance travelled per trip, the origin-destination (OD) matrices of the Flanders Multimodal Model (MMM) are used. The MMM is a macro traffic model that is developed since 1998 and is commissioned by the Flemish government. The matrices provided for this study simulate traffic on an average weekday between 4 am and 11 am (morning traffic). The zones, corresponding with the matrix, are in most places in line with census wards. The matrices are built on the basis of the 2001 census, which is an exhaustive survey of the Belgian population (excluding children under six years), assessing the address of residence and the address of the workplace (VERHETSEL et al., 2007). The processed data are aggregated by ward and present a picture of the daily travelled distances to and from each neighbourhood.

To obtain trip lengths, the shortest distance over the road network is calculated between the centroids of the connecting zones. Note that the distances calculated in this way are a slight underestimation of the real distances travelled, since detour factors associated with faster routes or the public transport network are not included (WITLOX, 2007). Since the fastest route depends on varying congestion levels, we aim to avoid added complexity and thus stick to calculating the shortest path. We calculate the average distance travelled per trip $\bar{h}(o b s)$ to and from each traffic analysis zone $i$ as follows: 


$$
\overline{h_{i}^{O}}(o b s)=\frac{\sum H_{i}^{o}}{\sum O_{i}} \quad \text { (1) } \quad \text { and } \quad \overline{h_{i}^{D}}(o b s)=\frac{\sum H_{i}^{D}}{\sum D_{i}}
$$

where $O$ and $D$, respectively, are the number of departing and arriving trips, and $H$ is the distance covered by each trip.

\subsubsection{Density (dens)}

As an approximation for the density we calculate the number of departing commuting trips, as well as the number of arriving trips per square kilometre, based on the MMM. Residential density is approximated by counting the number of outbound trips per square kilometre in the morning traffic. Job density is approximated by the density of inbound trips. We calculate the densities $C$ based on the number of outbound trips $O$ and the number inbound trips $D$ belonging to traffic analysis zone $i$ with area $A$ as follows:

$$
\mathrm{C}^{\mathrm{O}}{ }_{\mathrm{i}}=\mathrm{O}_{\mathrm{i}} / \mathrm{A}_{\mathrm{i}} \quad \text { (3) and } \quad \mathrm{C}^{\mathrm{D}}{ }_{\mathrm{i}}=\mathrm{D}_{\mathrm{i}} / \mathrm{A}_{\mathrm{i}}
$$

\subsubsection{Diversity (div)}

As a source, we used the Strucnet file of the NGI (NATIONAL GeOGRAPHICAL InSTITUTE OF BELGIUM, 2009) that contains all buildings represented on the official Belgian topographic maps with scale 1:10000. Different categories of buildings are distinguished but the accuracy of categorization is limited. All buildings that are morphologically part of a group of houses are listed as "ordinary building”. All other as such recognizable buildings (industry, schools, hospitals, public services etc.) have their own feature class. In practice this means that many commercial functions, offices and services that are interwoven with housing are not recognizable. Nevertheless, this inventory can be used to approximate diversity of functions in a given zone, and is without doubt the best currently available area-wide data set in Belgium. 
To calculate the spatial-functional diversity per zone, we apply the Shannon index. This index is used in landscape ecology as a measure of morphological diversity (NAGENDRA, 2002), and is in this case also called spatial entropy (BATTY, 1974). An extension to urban diversity is obvious. The Shannon index is calculated as follows:

$$
S_{i}=-\sum_{n=1}^{N} p_{n} \cdot \ln p_{n}
$$

in which $N$ is the number of features included within the considered aggregation zone $i$, and $p_{n}$ the proportion of each function that occurs within this zone.

\subsubsection{Minimum distance per trip (mdpt)}

We introduce the theoretical minimum commuting distance as a proxy for spatial proximity. The minimum commuting distance stems from the research on excess commuting (HAMILTON, 1982; MA and BANISTER, 2006; MA and BANISTER, 2007; CHARRON, 2007), and is in this case considered as a spatial characteristic (NIEDZIELSKI, 2006; BOUSSAUW et al., 2010).

The principle of the method implies linking any observed departure (in this case in the morning traffic) to the nearest observed arrival, also in the morning traffic. Per traffic analysis zone the number of departures, as well as the number of arrivals, is retained, but the existing relationship between origins and destinations is cut with the aim of minimizing the total travelled distance within the system. This theoretical exercise deliberately disregards non-spatial factors that determine the real world match between origin and destination. When commuting trips are considered, this means that everyone who is part of the active population is considered suitable to perform any job.

In BoussAuW et al. (2010) an algorithm was developed to calculate the local values of minimum commuting distance, based on the MMM, for the commute occurring between 4 am and $11 \mathrm{am}$. The algorithm obtains a general minimization of travel distances via local optimization, simulating individuals pursuing a job closer to home. For each traffic analysis zone, the calculation was done 
twice: once with the zone considered as an origin (outbound travel), and once with the zone considered as a destination (inbound travel). The first computed value is seen as an approximation for the proximity of housing within the zone in relation to the Flemish and Brussels labour market, while the second value is representative of the proximity of the labour market of the zone in relation to housing in Flanders and Brussels. We calculate the average minimum distance to be covered $\bar{h}(\mathrm{~min})$ per trip from and to a traffic analysis zone $i$ as follows:

$$
\overline{h_{i}^{O}}(\min )=\frac{\sum \min \left(H_{i}^{O}\right)}{\sum O_{i}} \quad \text { (6) and } \quad \overline{h_{i}^{D}}(\min )=\frac{\sum \min \left(H_{i}^{D}\right)}{\sum D_{i}}
$$

where $\min (H)$ is the minimized commuting distance per zone.

\subsubsection{Jobs-housing balance (jhb)}

The jobs-housing balance is the ratio between the number of jobs localized in a zone and the number of working people who live in the same zone. Because of its simplicity, this indicator is often used as a spatial characteristic in commuting research (CERVERO, 1989; PENG, 1997; HORNER and MURRAY, 2003; see HORNER (2004) for an overview).

We calculate the jobs-housing balance for every traffic analysis zone $i$, based on the MMM, by dividing the number of arrivals in the morning traffic by the number of departures:

$$
\mathrm{B}_{\mathrm{i}}=\mathrm{D}_{\mathrm{i}} / \mathrm{O}_{\mathrm{i}}
$$

\subsubsection{Number of potentially accessible jobs (potjob)}

The accessibility of the job market is also included in the analysis, and is expressed as the number of jobs, located in Belgium, that can be reached from every zone. Accessibility, departing from a particular zone, is determined by combining a probability curve with the travel time between the 
considered zone and all other zones in Belgium, after which the values for all these other zones are summed. The probability distribution was deducted from empirical data, while the travel time was calculated on the basis of a network with attributed impedances. The basic data on the location of jobs was provided by the FEDERAL PUBLIC SERVICE OF ECONOMY (2001) and is aggregated by borough (i.e. a municipality in the former administrative system).

The number of jobs accessible from a borough $i$ is defined as follows:

$$
A_{i}=\sum_{j=1}^{n} J_{j} \cdot F\left(c_{i j}\right)
$$

where $A_{i}$ is the number of jobs accessible from the considered borough $i, J_{j}$ the number of jobs located in each borough $j$, and $F\left(c_{i j}\right)$ the impedance function, based on the modelled probability curve.

We adopt the calculated results from VANDENBULCKE et al. (2007; 2009), and refer to these two papers for the exact calculation method. This accessibility index is related to the jobs-housing balance, but also takes into account the travel time needed to reach the core of the labour market.

\subsection{Level of aggregation and MAUP}

In order to discover correlations, we need to aggregate the various parameters within the same zonal classification. The traffic analysis zones of the MMM are not suitable for this. These zones are small in high density regions and vice versa, which apparently results - among other objections - in a nonnormal distribution of the variables linked to these zones. The large dispersion in area size makes the traffic analysis zones unsuited for the calculation of the Shannon index, which is area dependent, and also the calculation of the number of accessible jobs was initially based on another zoning (boroughs). For the sake of uniformity, we choose to aggregate all data into a grid of square cells.

However, the choice of the size of these cells is not evident. It is a well-known phenomenon that statistical correlations change whenever a different level of spatial aggregation is chosen, and that these become generally stronger when the aggregation level increases, even if accuracy of the data is 
in fact lost by increasing the aggregation level (AMRHEIN, 1995). This mechanism is called the scale effect of the MAUP, and is inherent in any quantitative analysis of spatially aggregated data.

OPENSHAW and TAYLOR (1979) argue that the choice of the aggregation level should depend on the expected significance for the studied variables. However, this suggestion does not solve the question. Our main variable, average trip length, shows important dispersion. Even if we choose the mesh size of the grid so that the average trip has its destination in a zone adjacent to the zone of origin, this will often not be the case for trip lengths deviant from this average. In this context, "mesh size" points to the length of a side of a cell in a uniform square grid. Regarding the independent variables it is even less clear what an appropriate level of aggregation would be.

To support the choice of a suitable aggregation level, in the exploratory stage we applied four different grids, with a mesh size of 1, 4, 8 and 16 kilometres. These options are illustrated in Figures 1, 2, 3 and 4 for one example (i.e. trip length). The results of a spatial correlation analysis (see below) indicate that the absolute values of the coefficients increase and that significances weaken along with an increase of the aggregation level. This finding confirms the expected influence of the MAUP.

The highest level of aggregation $(16 \times 16 \mathrm{~km})$ seems inappropriate because of the large number of nonsignificant relationships that are revealed by means of spatial regression, due to the reduced dataset size. The lowest level of aggregation $(1 \mathrm{x} 1 \mathrm{~km})$ also seems inapplicable: the relatively high degree of discontinuity between adjacent cells makes it sometimes difficult to clearly distinguish local patterns, resulting in often very low coefficients. Therefore, for the current analysis we choose an intermediary level of aggregation with a mesh size of $4 \mathrm{~km}$ (Figure 2). If we take into account a general detour factor of 1.40 (RIETVELD et al., 1999; WITLOX, 2007), then this choice implies that about $70 \%$ of all commuters have their destination in another zone than the origin zone of their trip (ZWERTS and NUYTS, 2004). 


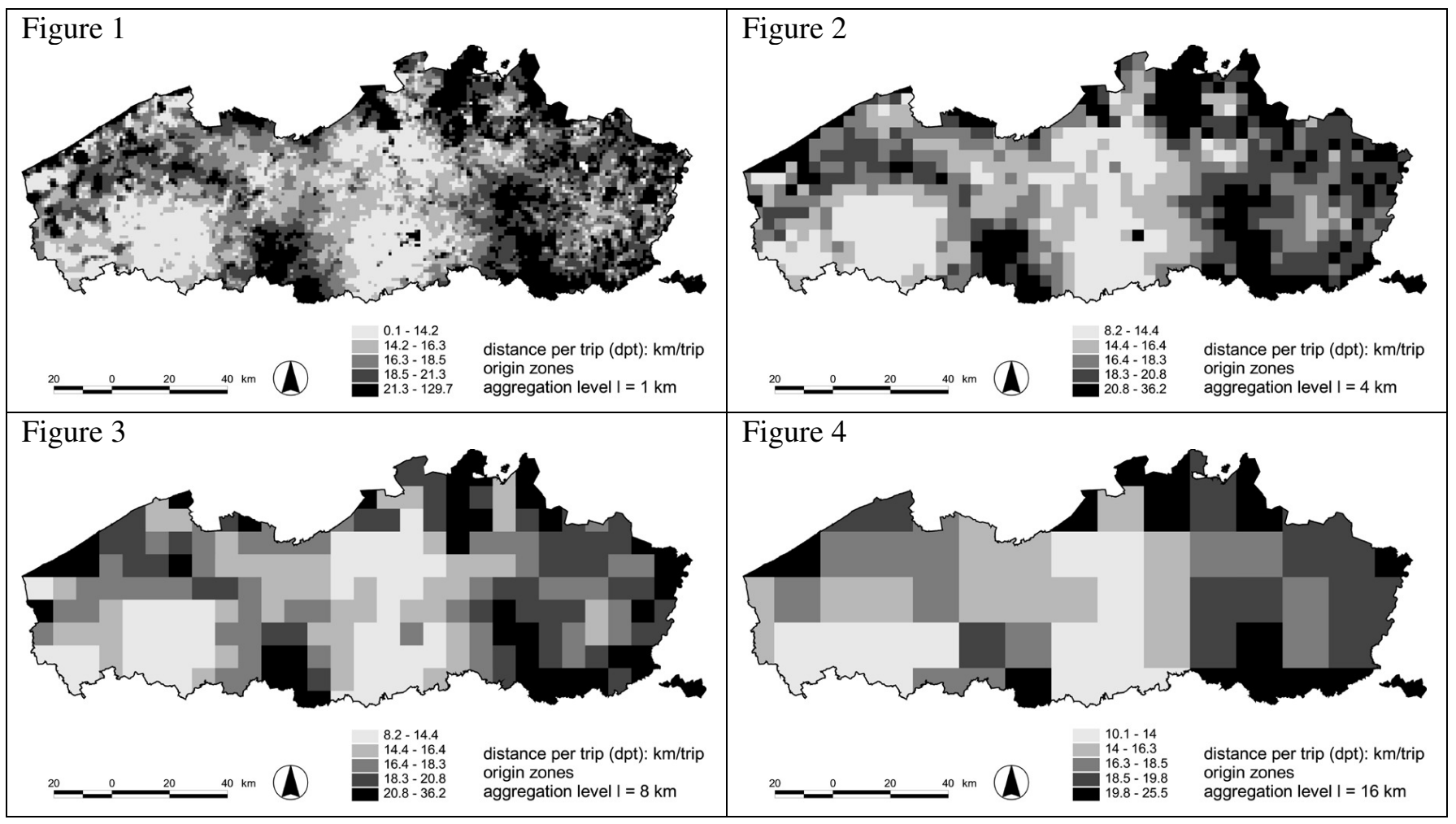

For the construction of the grid, the border zones of the study area are joined so that any cell size approaches the area of a square cell. The aggregation of those data that were originally available at the level of traffic analysis zones (i.e. travelled distance, density, minimum commuting distance and jobshousing balance) or borough (access to jobs) is done proportionally to the geographical overlap between two geographical divisions. The Shannon index (diversity) is calculated once for the grid with a mesh size of $1 \mathrm{~km}$, and then aggregated to the applied scale level.

\subsection{Spatial regression}

Given the nature of the examined spatial characteristics, an important degree of positive spatial autocorrelation between the zones themselves occurs. Spatial autocorrelation is the correlation between values of a variable that has its origin in the vicinity of the locations where these values are measured. Positive spatial autocorrelation, meaning that neighbouring areas are similar, is a phenomenon that is typically present in most empirical spatial datasets, and is explained by Tobler's first law of geography, in that "Everything is related to everything else, but near things are more 
related than distant things" (TOBLER, 1970). The presence of spatial autocorrelation is a violation of the assumption of independence of successive observations, which must be satisfied before applying classical statistical techniques such as correlation and regression analysis. Positive spatial autocorrelation leads too often to positive results of significance tests, and thus to the unjustified rejection of null hypothesises, and to an overestimation of regression and determination coefficients (ANSELIN and GRIFFITH, 1988).

Like the MAUP, spatial autocorrelation has often been ignored in past spatial planning studies. One of the reasons for the neglect of these issues in research applications is that the theoretical study of useful spatial alternatives to traditional statistical methods has been debated for a long time (CLIFF and ORD, 2009). An alternative regression method that was adopted by many authors is the so-called "spatial regression" technique, developed by Anselin (ANSELIN and BERA, 1998). This method starts from a significance test for spatial autocorrelation based on the calculation of Moran's I, a measure of spatial autocorrelation. If this test is not significant, the application of an ordinary least squares (OLS) regression is suggested. If the Moran's I test is significant (this is usually the case), the occurring kind of spatial dependence ("spatial lag" or "spatial error") should be detected. The occurrence of spatial lag implies that the dependent variable in a cell is not only affected by the independent variables in the cell itself, but also by those of the neighbouring cells. In the case of spatial error, only the residuals in the regression analysis of neighbouring cells are correlated. Depending on the occurrence of spatial lag or spatial error, a regression model is selected that reduces the influence of these phenomena. In some cases, both the spatial lag and the spatial error model can be applied. Each of these calculations provides, inter alia, a regression coefficient, a significance test and a pseudo coefficient of determination (pseudo $\mathrm{R}^{2}$ ). The relative popularity of this method in the recent literature is probably due to the user-friendly implementation in the freely distributed software tool GeoDA (ANSELIN et al., 2006). In this study, models were estimated by means of GeoDa 0.9.5-i5, which is a public domain software package making spatial regression techniques available in a GIS environment. The software was developed by dr. Luc Anselin, School of Geographical Sciences and Urban Planning, Arizona State University. 


\section{4. $\quad$ Results}

\subsection{Cartographic analysis}

In order to gain a better understanding of the spatial variations of the variables, we make a cartographic representation in Figures 5 to 13, aggregated at an intermediate scale in a grid of 4 by 4 km. Figure 14 shows a schematic reference of the study area (Flanders and Brussels). The variables distance per trip, minimum commuting distance and density are each shown twice: once the zones are regarded as origins and once the zones are regarded as destinations. The variables diversity, jobshousing balance and number of potentially accessible jobs are displayed once.

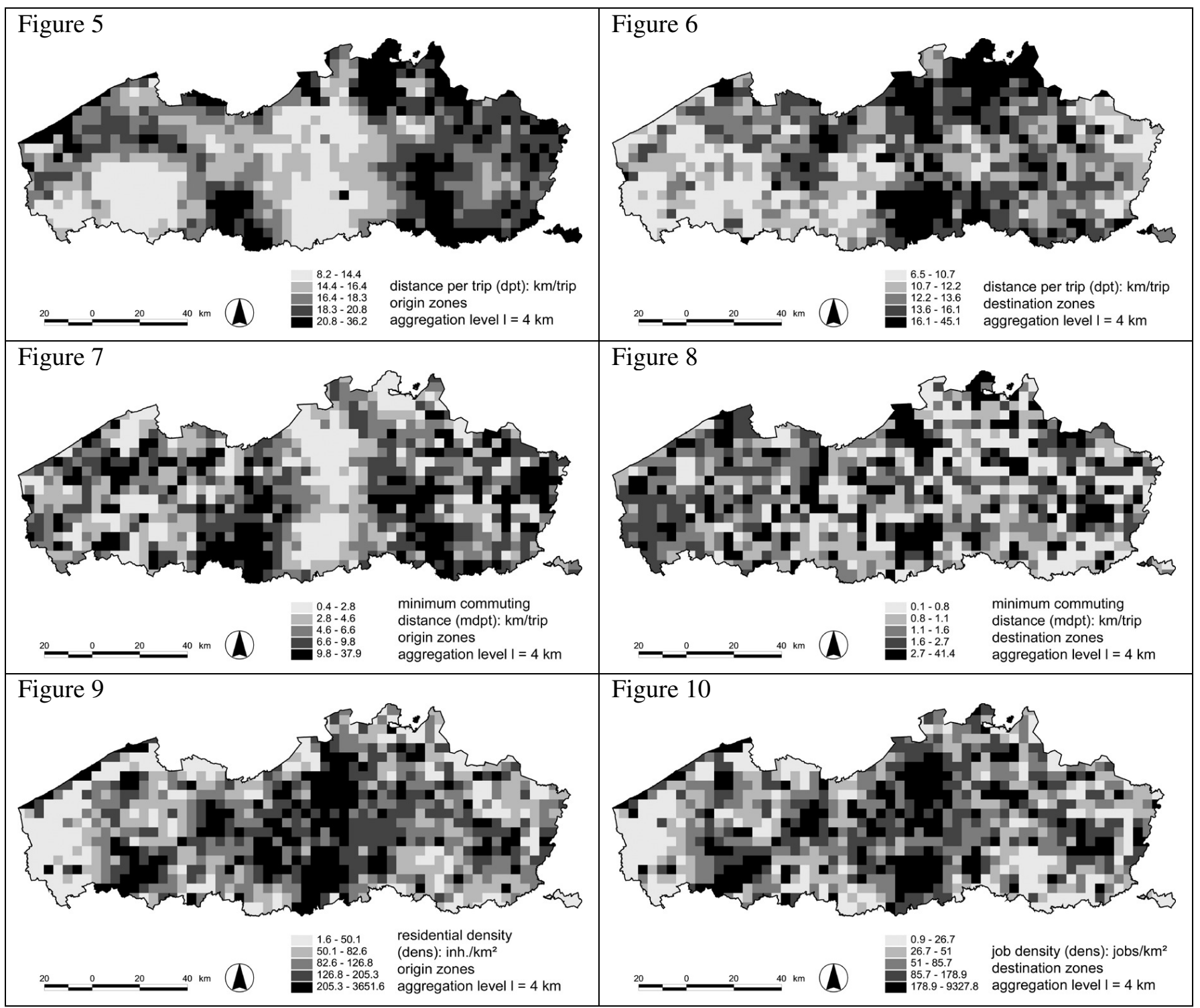




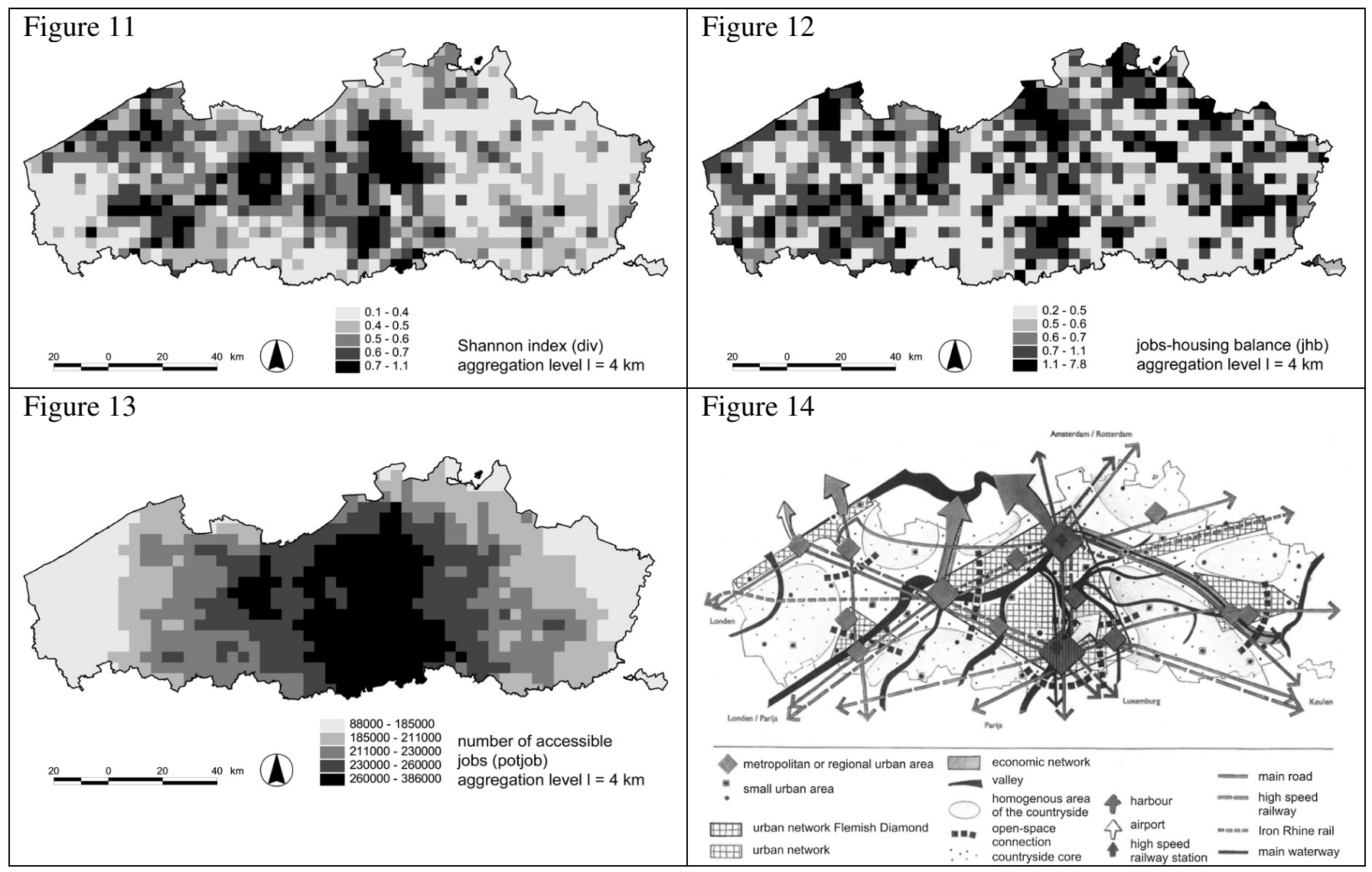

Before using this data in a statistical spatial analysis, we can already note a number of interesting findings from the maps.

The most obvious relationships can be seen in the maps where the zones are considered origins, or residential zones (Figs. 5, 7 and 9). The spatial variations of the distance travelled per trip (Fig. 5) is in most regions similar to the spatial pattern of the minimum commuting distance (Fig. 7), although values of the second variable are of course considerably lower. The map showing residential density (Fig. 9) is in many regions quasi the opposite of Figure 5 and Figure 7. Therefore, there seems to be a link between high residential densities and short commuting distances. The map of the spatial diversity distribution (Fig. 11) seems to indicate the same kind of relationship, at least as far as we consider the origin zones. The low measured spatial diversity in the province of Limburg (in the east) is noticeable. On the maps where the zones are regarded as destination or labour zone (Figs. 6 and 8), the patterns are less consistent. Here the thorough spatial concentration of jobs, in comparison with the more 
dispersed structure of housing, plays an important role. In areas with a low job density the value of the minimum commuting distance is of little significance.

A comparison of Figure 10 with Figures 6 and 8 indicates that job density is correlated with commuting distance, as well as with the minimum commuting distance to the destination areas. For a better insight, also the jobs-housing balance (Fig. 12) should be taken into account. In theory, a jobshousing balance fluctuating around 1 would be most likely to yield short commuting distances (PENG, 1997). Because of the large differences in spatial concentration between housing and jobs, Fig. 12 does not seem to support this theory at the first sight. The jobs-housing balance therefore requires more specific attention in the following paragraphs. In the economic core of Flanders there also seems to be a correlation between the accessibility of the job market (Fig. 13) and the distance travelled, while this relationship is much less clear in the rest of Flanders.

\subsection{Correlation analysis for the average distance travelled per trip}

All the independent variables are considered approximations for spatial proximity, in this case between the housing market and the job market. A Pearson's correlation matrix shows that most coupled variables in the origin zones exhibit correlations in the range of 20 to $50 \%$, amounting even to $72 \%$ (between job density and minimum commuting distance) in the destination zones. The couple job accessibility and jobs-housing balance is an exception, with a correlation coefficient of only $9,7 \%$.

Because of this inherent multicollinearity, and because of the difficulties regarding interpretation, we will not apply multiple regression techniques but confine ourselves to a bivariate correlation analysis.

We normalize all variables to $\mathrm{z}$-scores and subsequently include them in a bivariate spatial regression using GeoDA. The average distance travelled is always regarded as the dependent variable. For the spatial lag and spatial error models, spatial weight matrices are constructed on the basis of the grids, according to the so-called "queen" method. This means taking into account the influence of all adjacent cells, including these cells that touch the studied cell with only one point, like the adjacent squares in chess that are covered by the queen. 
First an OLS regression is done, as well as a test on spatial autocorrelation (through a significance test for Moran's I), and the presence of spatial lag and spatial error is detected. In case no significant spatial autocorrelation is found, the results of the OLS regression would be selected. In the other case, the spatial lag or spatial error model is applied, depending on which phenomenon is significant. If both phenomena appear significant, we apply both models. Each time we select the regression coefficient $r$, which can be considered as a spatial correlation coefficient, and the value of the significance test. We regard the zones firstly as origins and secondly as destinations. The results are presented in Table 1.

Table 1: Results of the correlation analysis for the average distance travelled per trip

\begin{tabular}{|c|c|c|c|c|c|c|c|c|}
\hline origin & MI & $p \mathrm{MI}$ & $r O L S$ & $p$ OLS & $r \mathrm{SL}$ & $p \mathrm{SL}$ & $r \mathrm{SE}$ & $p \mathrm{SE}$ \\
\hline dens & 0.628 & 0.000 & $(-0.318)$ & 0.000 & $\begin{array}{l}-0.098 \\
\end{array}$ & 0.000 & $(-0.109)$ & 0.000 \\
\hline $\operatorname{div}$ & 0.609 & 0.000 & $(-0.448)$ & 0.000 & -0.162 & 0.000 & -0.229 & 0.000 \\
\hline mdpt & 0.643 & 0.000 & $(0.255)$ & 0.000 & 0.080 & 0.000 & 0.070 & 0.003 \\
\hline jhb & 0.680 & 0.000 & $(0.040)$ & 0.237 & 0.019 & 0.322 & 0.029 & 0.223 \\
\hline potjob & 0.631 & 0.000 & $(-0.409)$ & 0.000 & $(-0.093)$ & 0.000 & -0.292 & 0.000 \\
\hline
\end{tabular}

\begin{tabular}{|c|c|c|c|c|c|c|c|c|}
\hline destination & MI & $p \mathrm{MI}$ & $r O L S$ & $p$ OLS & $r \mathrm{SL}$ & $p \mathrm{SL}$ & $r \mathrm{SE}$ & $p \mathrm{SE}$ \\
\hline dens & 0.655 & 0.000 & $(0.209)$ & 0.000 & $\mathbf{0 . 0 5 6}$ & 0.004 & $(0.045)$ & 0.108 \\
\hline $\operatorname{div}$ & 0.677 & 0.000 & $(0.095)$ & 0.005 & 0.020 & 0.302 & 0.012 & 0.678 \\
\hline mdpt & 0.624 & 0.000 & $(0.426)$ & 0.000 & 0.185 & 0.000 & 0.224 & 0.000 \\
\hline jhb & 0.576 & 0.000 & $(0.467)$ & 0.000 & 0.191 & 0.000 & 0.202 & 0.000 \\
\hline potjob & 0.653 & 0.000 & $(0.292)$ & 0.000 & $(0.004)$ & 0.829 & 0.171 & 0.014 \\
\hline
\end{tabular}

origin:

destination:

each zone is considered as an origin

between brackets:

each zone is considered as a destination

MI:

$p \mathrm{MI}$ :

the GeoDA model suggests not to use this method

Moran's I

p-value associated with Moran's I

$r$ OLS:

correlation coefficient (OLS method)

$p$ OLS:

p-value associated with OLS method

$r \mathrm{SL}:$

correlation coefficient ("spatial lag"-method)

(bold = significant at the 0.05-level)

$p \mathrm{SL}:$

p-value associated with "spatial lag"-method

$r \mathrm{SE}$ :

correlation coefficient ("spatial error"-method)

(bold = significant at the 0.05-level)

$p \mathrm{SE}:$

p-value associated with "spatial error"-method

\subsubsection{Interpretation regarding the origin zones}

In this case, we consider each zone as a residential area, acting as a source of home-to-work trips in the morning traffic. For all variables, a significant amount of spatial autocorrelation was found, 
making the application of a simple linear regression (OLS) inappropriate. The applied spatial regression models were suggested by GeoDA. Except for the jobs-housing balance all variables show a significant relation with the distance travelled per trip. Below we give an overview of our findings.

- A higher population density is associated with shorter commuting distances.

- A greater diversity is also associated with shorter commuting distances. The link with spatial diversity is much stronger than the relationship with population density.

- The minimum commuting distance shows a positive correlation with the observed commuting distance, the magnitude of $r$ being similar as for the relationship with population density.

- There is no significant correlation between the observed commuting distance and the jobshousing balance. Given the specific characteristics of the job-housing balance we will devote a separate section to this variable below.

- Better access to the job market is associated with shorter commuting distances. In comparison with the other independent variables we can call this relationship strong.

\subsubsection{Interpretation regarding the destination zones}

Now, we consider each zone as a labour area, a destination of the commute during the morning. Again, we find significant spatial autocorrelation for all variables. The calculation of the spatial regression models suggested by GeoDA results in following findings:

- In contrast to the population density in the origin zones, a higher density of jobs in destination zones is associated with longer commuting distances. The relationship with job density is however less strong than the relationship with population density in the origin zones.

- There is no demonstrable correlation with spatial diversity.

- There is a relatively strong positive correlation between minimum commuting distance and observed commuting distance.

- Even if jobs-housing balance appears not relevant in the origin zones, this variable provides a relatively strong correlation in the destination zones. The higher the jobs-housing balance is, 
the larger the commuting distances. This finding should, however, be qualified (see next section).

- The interpretation of the influence of the number of potentially accessible jobs is not obvious, since this variable represents the number of jobs accessible departing from the considered zone, and not from the other zones. This parameter yields a positive $r$. Better access to the job market seen from the considered zone is associated with a concentration of jobs, and thus with longer commuting distances to this zone.

\subsection{Non-linearity in the jobs-housing balance}

The use of spatial correlation analysis assumes a linear relationship between the corresponding variables. This was assessed by the estimation of a Lowess curve in a scatter plot, showing indeed linearity for most of the used datasets. Lowess or Loess (locally weighted/estimated scatterplot smoothing) is a regression technique that applies linear least squares regression on segments of the data, yielding a smoothly fitted curve. However, slopes tend to flatten in the border areas of the sample curve. This is particularly the case when dealing with extremely high densities or large minimum commuting distances, or extreme values (both high and low) of accessibility. Only with regard to the jobs-housing balance the relationship is clearly not linear, especially when considering origin zones. At one hand, it seems logical that a higher jobs-housing balance leads to a larger share of nearby jobs, reducing average commuting distances. On the other hand, it is clear that a high jobs-housing balance in the destination zones is accompanied with an (over)concentration of jobs, leading to larger commuting distances. Thus, a high jobs-housing balance would be associated with both long and short commuting distances. This paradox stems from our assumption of linearity, which appears unjustified. When we consider the total amount of travelled distances produced per zone, adding the distances covered by inbound trips to these covered by the outbound trips, and plot this summed variable against the jobs-housing balance, we should obtain a U-shaped curve (PENG, 1997) (Fig. 15). The minimum distance corresponds to an equilibrium point where the jobs-housing balance is close to 1 , representing a perfectly equal spatial distribution of housing and jobs. 
To verify the validity of this hypothesis, we visualize the link between the total generated distance per zone $(4 \times 4 \mathrm{~km})$ and the jobs-housing balance by means of a scatter plot for which we estimate a Lowess curve and a best-fit quadratic curve (Fig. 16).

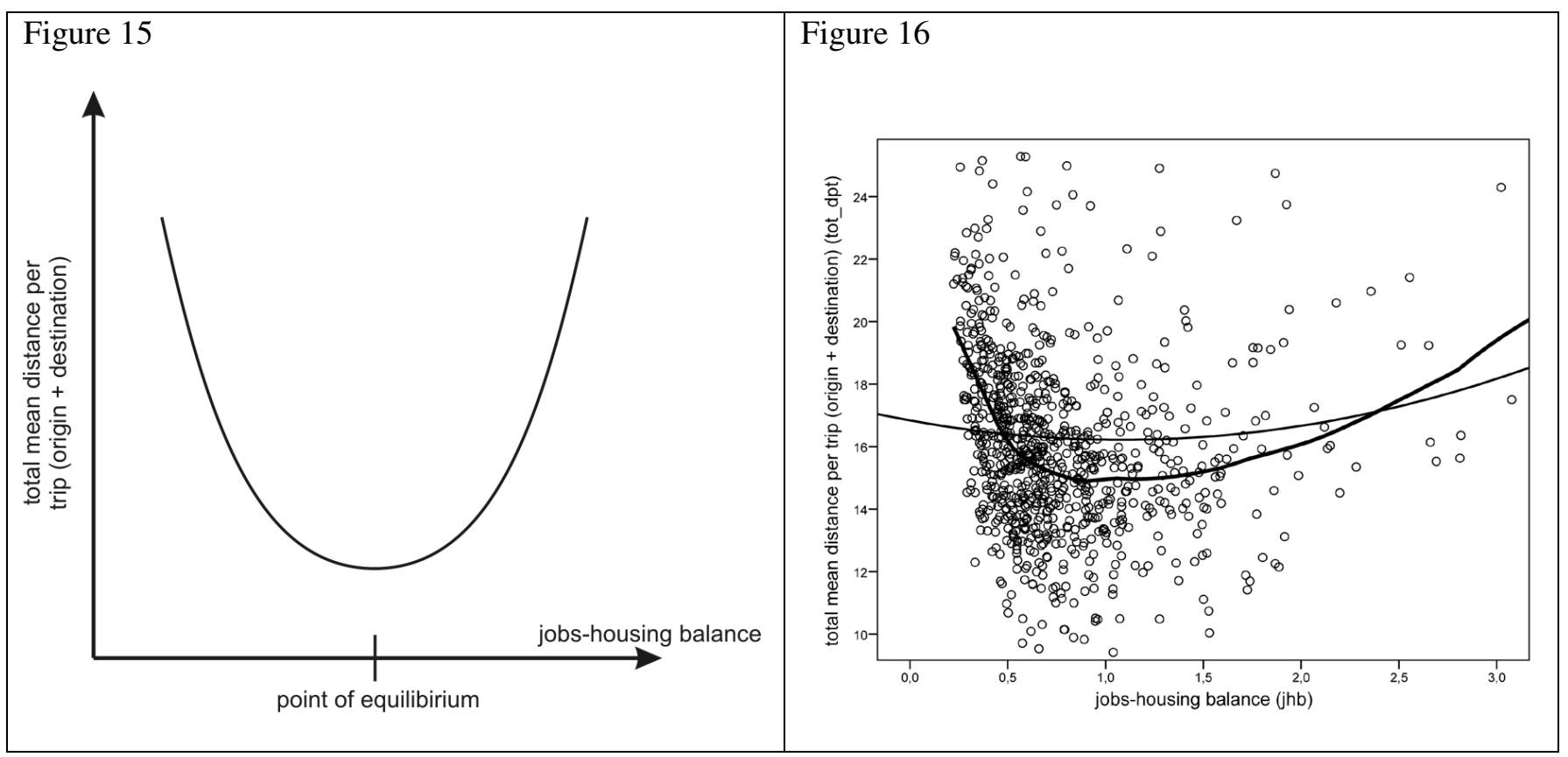

The curves appear to correspond to our hypothesis: i.e. the total commuting distance associated with one zone reaches a minimum at an optimal jobs-housing balance, which is situated around 1 . However, the fit is rather weak. This is partly due to the fact that there are many more zones with a low jobs-housing balance than with a high jobs-housing balance. Though, a more important reason is that the natural relationship between spatial segregation and trip length is disturbed and smoothed by non-spatial influences, as discussed in the introduction. The same reason applies to the generally low values of $r$ that were found in the previous section.

\section{Discussion}

\subsection{Origin versus destination zones}

For most parameters, a positive correlation with the outbound trip length corresponds with a negative correlation with the inbound trip length. A higher population density in an origin zone means shorter 
trips. A higher job density, by contrast, just means longer trips. We observe a similar pattern when considering the number of accessible jobs. With respect to spatial diversity, there seems to be no discernible relationship in the destination zones, while we should approach the jobs-housing balance in a non-linear way.

These results derive from the unequal spatial distribution of housing and jobs. Jobs occur more often than housing in high concentrations in urban areas, where the density and the spatial diversity is generally high. In most zones the jobs-housing balance is lower than 1, making job supply in the other zones, which are much less numerous, overconcentrated. Overconcentration means that employees more often come from very far away to take up available jobs. On the origin side, however, employees living in an area with urban characteristics (high density and spatial diversity) more often find a job close to home.

Therefore, NEWMAN and KenWORTHY's $(1989 ; 1999)$ thesis that fuel consumption is negatively correlated with density, is only valid when we consider the residential zones. In the case of the labour zones, we find an inverse correlation. However, modal choice was not taken up in this study. We can assume that zones with a very high job concentration are accessed more than average by public transport. Consequently, energy consumption (and other undesired external effects of traffic) is expected to grow slower than the travelled distance itself. But because the highest job concentrations entail the most extreme forms of long-distance commuting, this mitigating effect on fuel consumption will be rather limited.

Spatial diversity does not explain commuting distance viewed from the labour zones. This can be explained by the large differences in types of labour areas: high job concentrations generating long trips occur both in urban centres with a high spatial diversity and in isolated mono-functional industrial and port areas. This is different with regard to the residential areas, where diversity is an explaining factor: a high residential density is usually associated with a large supply of jobs, and thus a sound spatial mix of both functions.

When considering the relationship between the observed commuting distance and the minimum commuting distance, values of $r$ are significantly higher for labour areas compared to residential areas. 
However, the relationship with job density (in the labour areas) is weaker if we compare to the relationship with housing density (in residential areas).

When we examine the origin zones, we conclude that job accessibility and spatial diversity should be considered the most appropriate indicators influencing commuting trip length. In this case, residential density and minimum commuting distance have a relatively low predictive value, while jobs-housing balance is not a linear predictor at all. In the destination zones, however, the minimum commuting distance is a relatively good indicator, while the jobs-housing balance and job density have only conditional predictive value.

\subsection{Relevant scale levels}

We have to take into account that the relationships that we derive from an analysis at the level of zones of $4 \times 4 \mathrm{~km}$ cannot necessarily be extended to processes that play at a different aggregation level. The importance of scale may mainly depend on the considered trip length classes.

Density, diversity and proximity are spatial characteristics that are important for traffic generation, but mainly on a scale level that can be associated with the considered distance class. Influencing travel behaviour of motorists should be done especially at higher scale levels. To influence trips of pedestrians, cyclists and users of local public transport, the lowest scale levels are perhaps the most relevant.

The travel behaviour of the 21 st century commuter deviates strongly from that of the historical inhabitants of a medieval or nineteenth-century compact city, so that only a limited overall environmental impact is to be expected of a policy that only focuses on strengthening these old structures. Potentially more impact could be expected from a policy that focuses on strengthening density, diversity, jobs-housing balance and proximity within the higher levels of aggregation, comprising also suburban areas. In addition, the quality of the urban structure on the lowest scale levels may still have an impact on the share of pedestrians, cyclists and users of public urban transport, and may in that sense have a positive impact on the urban environment. 


\section{Conclusions and pathways for further research}

Daily trips on foot, by bike or public urban transport, but also short car trips, fit into the spatial model of the compact city. By strengthening the characteristics of the compact city, with the emphasis on residential density and proximity of functions, a spatial framework may be created that makes trips over long distances less necessary or even unnecessary. However, the category of short trips has become a niche market, especially within the commute. In Flanders, the average commuter covers a distance of about 19 kilometres per trip, a trip length that is well beyond the compact urban scale. However, a number of qualities that are attributed to the compact city are still valuable, even if they also influence spatial processes at the regional scale. Viewed from a sustainability perspective, an equal jobs-housing balance and a high residential density are paramount. A high degree of spatial diversity and accessibility of the labour market play also a positive role. By contrast, high concentrations of employment are not desirable. High job densities seem to give rise to overconcentration easily, so that workers should be recruited from a wide hinterland. These features are reflected in the minimum commuting distance, which is a good measure for the proximity of housing and the job market and clearly evolves parallel with the observed commuting distances. Since the minimum commuting distance is determined by the spatial patterns of housing, jobs and infrastructure, we can conclude that commuting over short distances can be facilitated by changes in the spatial structure.

The outlined research design, however, also calls for further elaboration. The results for the commute cannot simply be extrapolated to other types of travel. Trips to school, shops or social activities usually are much shorter than home-to-work trips (ZWERTS and NUYTS, 2004). Therefore, it might be possible that the correlations for this type of travel are stronger at the lower scale levels, in comparison to home-to-work trips. Another extension concerns the feasibility of an equal jobs-housing balance: it has to be taken into account that neighbourhood's jobs-housing balances fluctuating area-wide around 1 may not be compatible with agglomeration trends that are important for many economic sectors.

Another improvement could be incorporating the modal split in the comparisons. Long commuting distances are often covered by train, which means that the negative impact of these trips increase at a 
slower rate than the number of kilometres travelled. Moreover, it may well be that increasing spatial proximity at the lowest scale levels will result in a larger share of pedestrians, cyclists and users of urban public transport in urban areas, strengthening the positive effect of shorter trips by a modal shift. We hope to address these and related issues in future research.

\section{Acknowledgments}

This research has been made possible within the Flemish Policy Research Centre for Housing and Space, funded by the Ministry of the Flemish Community. The authors wish to express their thanks to the Flemish Traffic Control Centre for the assistance, to Grégory Vandenbulcke (Université Catholique de Louvain) for providing the accessibility data and to two anonymous referees for their useful comments.

\section{References}

ALBERTI M. (1999) Urban patterns and environmental performance: what do we know? Journal of Planning Education and Research 19, 151-163;

AMRHEIN C. G. (1995) Searching for the elusive aggregation effect: evidence from statistical simulations, Environment and Planning A 27, 105-119;

ANSELIN L. and BERA A. (1998) Spatial dependence in linear regression models with an introduction to spatial econometrics, in ULLAH A. and GILES D. (Eds) Handbook of Applied Economic Statistics, pp. 237-290. Marcel Dekker, New York;

ANSELIN L. and GRIFFITH D. A. (1988) Do spatial effects really matter in regression analysis? Papers in Regional Science 65, 11-34; 
ANSELIN L., SYABRI I. and KHO Y. (2006) GeoDa: An introduction to spatial data analysis,

Geographical Analysis 38, 5-22;

BANISTER D., WATSON S. and WoOD C. (1997) Sustainable cities, transport, energy and urban form, Environment and Planning B 24, 125-143;

BATTY M. (1974) Spatial entropy, Geographical Analysis 6, 1-31;

BOUSSAUW K. and WITLOX F. (2009) Introducing a commute-energy performance index for Flanders, Transportation Research Part A 43, 580-591;

BoussauW K., NeUtens T. and Witlox F. (2010) Minimum commuting distance as a spatial characteristic in a non-monocentric urban system: the case of Flanders, Papers in Regional Science 89;

BURTON E. (2000) The potential of the compact city for promoting social equity, in WILLIAMS K., Burton E. and JenKS M. (Eds) Achieving Sustainable Urban Form, E\&FN Spon, London and New York;

CERVERO R. (1989) The jobs-housing balance and regional mobility, Journal of the American Planning Association 55, 136-150;

Cervero R. (1996) Mixed land-uses and commuting: Evidence from the American housing survey, Transportation Research Part A 30, 361-377;

CERvero R. and Kockelman K. (1997) Travel demand and the 3Ds: Density, diversity, and design, Transportation Research Part D 2, 199-219; 
CHARRON M. (2007) From excess commuting to commuting possibilities: more extension to the concept of excess commuting, Environment and Planning A 39, 1238-1254;

CLIFF A. D. and ORD J. K. (2009) What were we thinking? Geographical Analysis 41, 351-363;

COMMISSION OF THE EUROPEAN COMMUNITIES (1990) Green Paper on the Urban Environment $\operatorname{COM}(90) 218$, Brussels;

CRANE R. and CREPEAU R. (1998) Does neighborhood design influence travel? A behavioral analysis of travel diary and GIS data, Transportation Research Part D 3, 225-238;

DODSON J. and SIPE N. (2008) Shocking the suburbs: urban location, homeownership and oil vulnerability in the Australian city, Housing Studies 23, 377-401;

ELLIS C. (2002) The New Urbanism: critiques and rebuttals, Journal of Urban Design 7, 261-291;

FedERAL Public SERviCe ECONOMY (2009) Structuur van de Bevolking. Brussels, from http://statbel.fgov.be/figures/d21_nl.asp.

FRANK L. D. and PIVO G. (1994) Impacts of mixed use and density on utilization of three modes of travel: single-occupant vehicle, transit, and walking, Transportation Research Record 1466, 44-52;

HAMilton B. W. (1982) Wasteful commuting, The Journal of Political Economy 90, 1035-1053;

JenKS M., BurTON E. and WiLliams K. (1996) Compact cities and sustainability: an introduction, in Jenks M., Burton E. and WiLliams K. (Eds) The Compact City: a Sustainable Urban Form? pp. 38. E\&FN Spon London and New York; 
LYONS G. and CHATTERJEE K. (2008) A human perspective on the daily commute: costs, benefits and trade-offs, Transport Reviews 28, 181-198;

MA K. R. and BANISTER D. (2006) Excess commuting: a critical review, Transport Reviews 26, 749767

MA K. R. and BANISTER D. (2007) Urban spatial change and excess commuting, Environment and Planning A 39, 630-646;

MindALI O., RAVEH A. and SALOMON I. (2004) Urban density and energy consumption: a new look at old statistics, Transportation Research Part A. 38, 143-162;

Ministry OF Housing, SPATIAL PLANNING AND THE ENVIRONMENT (1988) Vierde Nota over de Ruimtelijke Ordening, The Hague;

MINISTRY OF THE FLEMISH COMMUNITY (1997/2004) Ruimtelijk Structuurplan Vlaanderen Gecoördineerde Versie, Brussels;

NAGENDRA H. (2002) Opposite trends in response for the Shannon and Simpson indices of landscape diversity, Applied Geography 22, 175-186;

NATIONAL GEOGRAPHICAL InSTITUTE OF BELgIUM (2009) Structuur en Codering van de Gegevens top10v-gis en top50V-gis. Brussels, from http://www.ngi.be/Common/articles/CA_Top10VGIS_TOP50V-GIS/restruct_doc_nl.htm;

NeUman M. (2005) The compact city fallacy, Journal of Planning Education and Research 25, 11-26; 
NEWMAn P. and Kenworthy J. (1999) Sustainability and Cities: Overcoming Automobile Dependence. Island Press, Washington DC;

Newman P. and Kenworthy J. (1989) Cities and Automobile Dependence. A sourcebook. Gower, Aldershot;

NiEDZIELSKI M. A. (2006) A spatially disaggregated approach to commuting efficiency, Urban Studies 43, 2485-2502;

OPENSHAW S. and TAYLOR P. (1979) A million or so correlation coefficients: three experiments on the modifiable areal unit problem, in WRIGLEY N. (Ed) Statistical Methods in the Spatial Sciences, pp. 127-144. Routledge and Kegan Paul, London;

PENG Z. R. (1997) The jobs-housing balance and urban commuting, Urban Studies 34, 1215-1235;

RIETVELD P., ZWART B., VAN WEE B. and VAN DEN HOORN T. (1999) On the relationship between travel time and travel distance of commuters. Reported versus network travel data in the Netherlands, The Annals of Regional Science 33, 269-287;

SCHWANEN T. and MOKHTARIAN P.L. (2005a) What if you live in the wrong neighborhood? The impact of residential neighborhood type dissonance on distance traveled, Transportation Research Part D 10, 127-151;

SCHWANEN T. and MOKHTARIAN P. L. (2005b) What affects commute mode choice: neighborhood physical structure or preferences toward neighborhoods? Journal of Transport Geography 13, 83-99; 
StEAD D., WiLliams J. and TiTHERIDGE H. (2000) Land use, transport and people: identifying the connections, in WiLliams K., BURTON E. and JenKs M. (Ed) Achieving Sustainable Urban Form, pp. 174-186. E\&FN Spon, London and New York;

ToBLER W. R. (1970) A computer movie simulating urban growth in the Detroit region, Economic Geography 46, 234-240;

VAN ACKER V. and WITLOX F. (2010) Commuting trips within tours: how is commuting related to land use? Transportation (forthcoming);

VAN ACKeR V., WitLOX F. and VAN WEE B. (2007) The effects of the land use system on travel behavior: A structural equation modeling approach, Transportation Planning and Technology 30, 331353 ;

VAN WEE B. (2002) Land use and transport: research and policy challenges, Journal of Transport Geography 10, 259-271;

VAndenbulcKe G., SteEnberghen T. and ThOMAs I. (2007) Accessibility Indicators to Places and Transports - Final Report, Federal Public Service Mobility / Federal Science Policy, Leuven / Louvain-la-Neuve;

VAndenbulcke G., Steenberghen T. and Thomas I. (2009) Mapping accessibility in Belgium: a tool for land-use and transport planning? Journal of Transport Geography 17, 39-53;

Verhetsel A., Thomas I., Van Hecke E. and Beelen M. (2007) Pendel in België. Deel I: de Woon-Werkverplaatsingen, Federal Public Service Economy, Brussels; 
WANG F. (2000) Explaining intraurban variations of commuting by job proximity and workers' characteristics, Environment and Planning B 28, 169-182;

WANG F. (2003) Job proximity and accessibility for workers of various wage groups, Urban Geography 24, 253-271;

WiLliams K., BURTON E. and JenKS M. (2000) Achieving sustainable urban form: an introduction, in Williams K., Burton E. and JenKs M. (Eds) Achieving Sustainable Urban Form, pp. 1-5. E\&FN Spon, London and New York;

WITLOX F. (2007) Evaluating the reliability of reported distance data in urban travel behaviour analysis, Journal of Transport Geography 15, 172-183;

ZWERTS E. and NUYTS E. (2004) Onderzoek Verplaatsingsgedrag Vlaanderen 2000-2001, Ministry of the Flemish Community, Brussels / Diepenbeek. 